\title{
Vasculitis: Endothelial Dysfunction During Rickettsial Infection
}

\author{
Yassina Bechah, Christian Capo and Jean-Louis Mege \\ Unité de Recherche sur les Maladies Infectieuses Transmissibles et Emergentes (URMITE), \\ UMR CNRS 6236, IRD 3R198, Institut Fédératif de Recherche 48, Université de la \\ Méditerranée, Faculté de Médecine, 13385 Marseille, \\ France
}

\section{Introduction}

Rickettsial infections cause irreversible damage to the human host and are associated with a high morbidity and high mortality. The mortality rate can be as high as $20 \%$ for Rocky Mountain spotted fever and $30 \%$ for epidemic typhus, which are both diseases that are caused by rickettsiae. Some rickettsiae species, such as Rickettsia prowazekii and Rickettsia rickettsii, are currently considered bioterrorism agents. The study of rickettsiae organisms is fascinating due to the nature of these pathogens, which are obligate intracellular bacteria, and to their tropism for the endothelium. The endothelium plays a key role in numerous physiological processes, such as vascular homeostasis, the regulation of blood flow and vascular tone, coagulation, angiogenesis and inflammation. In this chapter, we give a general overview of rickettsial diseases, the endothelium, and how rickettsial infection impacts endothelial function. Specifically, we focus on the endothelial cell response to rickettsial infections and emphasize the role of the endothelial cells in the clinical symptoms and tissue injury caused by rickettsioses.

\section{Rickettsioses}

Rickettsioses are infectious diseases that are caused by heterogeneous, gram-negative, obligate intracellular bacteria (figure 1). The Rickettsiaceae bacterial family contains the genus Orientia, which has only one species (Orientia tsutsugamushi), and the genus Rickettsia. The Rickettsia genus contains two major groups: the spotted fever group (SFG) and the typhus group (TG). The SFG group includes Rickettsia conorii, which causes Mediterranean spotted fever, and $R$. rickettsii, which causes Rocky Mountain spotted fever, as well as several other species. The TG group (TG) includes only two species: Rickettsia typhi, which causes murine typhus, and $R$. prowazekii, which causes epidemic typhus. Rickettsioses may lead to irreversible damage in the host and ultimately patient death, especially with $R$. rickettsii and $R$. prowazekii infections. The mortality rates of $R$. rickettsii and $R$. prowazekii infection are estimated to be 20 and $30 \%$, respectively, in the absence of antibiotic treatment [Azad, 2007]. Rickettsiae are typically transmitted to humans and animals by infected arthropods, including ticks, mite, fleas and lice. However, several studies have shown that inhalation of contaminated aerosols or blood transfusions with contaminated samples may also transmit 
these diseases [Oster et al., 1977; Bechah et al., 2011; Wells et al., 1978]. Arthropods are the main reservoirs of rickettsiae, with the exception of $R$. prowazekii that kills lice some days after infection [Houhamdi et al., 2002].

Currently, the risk of contracting a rickettsiosis is increasing throughout the world, and the risk of outbreaks is especially high in countries at war or impacted by natural disasters. In addition, some rickettsiae, such as $R$. prowazekii, can survive within infected individuals for the lifetime of the host. Under intense stress, these latent bacteria can become active and cause Brill-Zinsser disease, which is a relapsing form of epidemic typhus [Saah, 2000]. This form of infection may be the source of new epidemic typhus outbreaks, especially if louse infestation is prevalent.

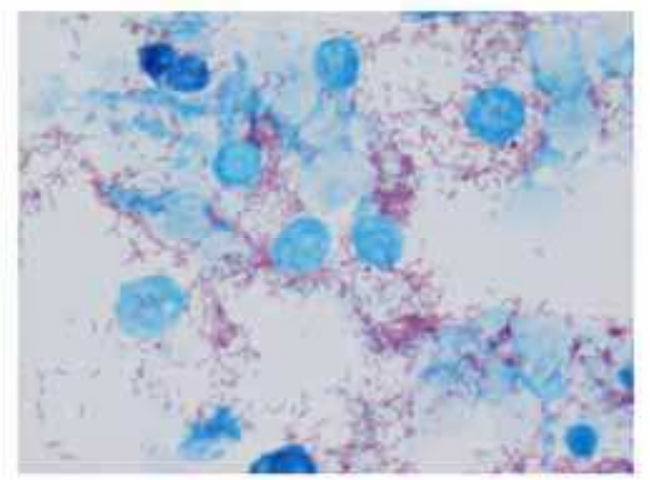

Fig. 1. Gimenez staining of $R$. prowazekii (red) in the cytoplasm of L929 cells (blue).

$R$. prowazekii and $R$. rickettsii have been classified as biological weapons according to the Centers for Disease Control and Prevention. Rickettsiae pathogens are often stable in an environment outside the host, are infectious at low doses, may be transmitted to humans or animals through aerosols and may persist in infected individuals for the rest of their life, becoming re-active and infectious at any moment.

The rickettsial genome size is small and ranges from $1.1 \mathrm{Mb}$ for TG rickettsiae to $1.5 \mathrm{Mb}$ for $R$. bellii [Merhej et al., 2009; Blanc et al., 2007; Andersson \& Andersson S. G. E., 1999]. Because of their reduced genomes, rickettsiae depend on interactions with the infected host eukaryotic cells for survival. In humans, rickettsioses are associated with a large spectrum of clinical symptoms, including fever, rash, headache, myalgia and arthromyalgia. Rickettsiae tend to target and replicate in the vascular endothelium, especially within small vessels. Bacterial infection and replication in the endothelium often results in vasculitis (figure 2A), and the morbidity and mortality caused by rickettsioses appear to be a consequence of vascular injury, inflammation and thrombotic complications.

\section{Endothelium}

The endothelium is a monolayer of cells that line the interior of the blood and lymphatic vessels. This cellular layer is attached to the basal membrane and participates in the exchange of materials between the blood and tissues. The endothelium consists of about $10^{13}$ cells [Augustin et al., 1994] and weighs approximately $1 \mathrm{~kg}$ in humans [Ait-Oufella et al., 
2010; Sumpio et al., 2002]. Endothelial cells are approximately $100 \times 10 \mu \mathrm{m}$ in size and are tightly connected to each other, which helps to maintain the vascular integrity. Endothelial cells exhibit a large degree of plasticity and heterogeneity, and their morphology is influenced by their environment [Davies, 1995; Allaire and Clowes A. W., 1997; Steinsiepe and Weibel E. R., 1970; Ishii et al., 1986; Tse and Stan R. V., 2010]. For example, arterial endothelial cell morphology is different from venous endothelial cell morphology; interestingly, venous endothelial cells that are subjected to increased shear flow elongate and resemble endothelial cells from arteries [Allaire and Clowes A. W., 1997].
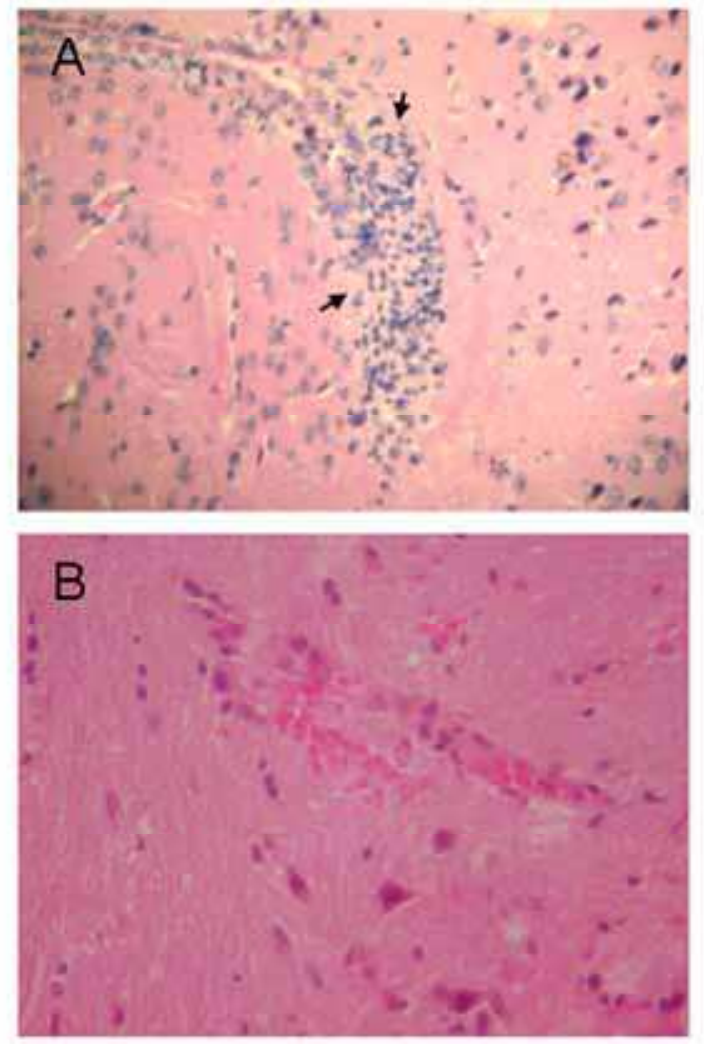

Fig. 2. Brain lesions induced by $R$. prowazekii Mice are infected with $R$. prowazekii for 7 days. Sections $(5 \mu \mathrm{m})$ of paraffin-embedded brain are stained with hematoxylin-eosin to assess the presence of lesions. A. Note vasculitis composed mainly of mononuclear cell infiltrates. B. Note hemorrhage in the brain parenchyma. Original magnifications, X 200.

Endothelial cells release a multitude of biological mediators, such as growth factors (e.g., transforming growth factor, basic fibroblast growth factor), vasoactive mediators (e.g., prostacyclin, nitric oxide (NO), endothelin and angiotensin), coagulation and fibrinolysis proteins (e.g., thrombomodulin, heparin, tissue factor, plasminogen activator inhibitor, platelet activating factor, von Willebrand factor) and immune factors, including cytokines, chemokines and adhesion molecules [Ait-Oufella et al., 2010]. Because the endothelium 
controls the release of these molecules, endothelial cells have been implicated in numerous processes, including vascular homeostasis, coagulation, fibrinolysis, the regulation of blood flow and vasomotor tone, angiogenesis, the regulation of leukocyte adhesion/migration and inflammation [McGettrick et al., 2007]. In addition to their implied role in the innate immune response, endothelial cells express major histocompatibility complex class I and class II molecules and co-stimulation molecules, such as CD86 and CD58, which allow endothelial cells to directly interact with $\mathrm{CD}^{+}$and $\mathrm{CD}^{+} \mathrm{T}$ lymphocytes [Pober et al., 1996; Marelli-Berg et al., 1996; Ait-Oufella et al., 2006].

\section{Rickettsia-endothelial cell interactions}

In vertebrate hosts, rickettsiae typically target the microvascular endothelium (figure 3) and damage the endothelial cells. Studies have shown that rickettsiae bind to the membrane receptor Ku70, which is a component of the DNA-dependent protein kinase that is present at the surface of endothelial cells. The molecular nature of the rickettsial ligands of Ku70 has been determined; they include OmpB, which is expressed by both SFG and TG rickettsiae [Uchiyama, 2003], and OmpA, which is only expressed by SFG [Li and Walker D. H., 1998]. $\mathrm{OmpB}$ and OmpA are outer membrane proteins that belong to a large rickettsial surface cell antigen family (sca) [Blanc et al., 2005]. Studies have shown that monoclonal antibodies against OmpB and/or OmpA significantly decrease rickettsial infection of endothelial cells both in vitro and in vivo, and administration of these antibodies protects mice from death [Li and Walker D. H., 1998; Feng et al., 2004]. Additional rickettsial adhesion proteins that play a role in host cell entry have been recently identified, they include the proteins RC1281 and RP828 identified in $R$. conorii and $R$. prowazekii, respectively [Renesto et al., 2005a; Renesto et al., 2006]. After binding to endothelial cells, rickettsiae are actively internalized by the endothelial cells [Walker, 1984; Li and Walker D. H., 1992].

To avoid destruction within the phagosome, rickettsiae have developed a strategy to rapidly escape from phagosomes and relocate to the cytosol prior to phagolysosomal fusion [Teysseire et al., 1995]. Phagosome escape appears to be mediated by the hemolysin C (Tly C) and phospholipase D (PLD) proteins, as demonstrated by the complementation of Salmonella enterica by the genes encoding Tly C and PLD [Whitworth et al., 2005; Renesto et al., 2003]. Moreover, a $R$. prowazekii Evir strain pld mutant has decreased virulence in a guinea pig model. Interestingly, immunization of the guinea pigs with this mutant protects them from infection with subsequent challenges with a virulent strain of $R$. prowazekii (Breinl strain) [Driskell et al., 2009].

Once in the cytoplasm, rickettsiae acquire nutrients from their host cells through transmembrane exchange proteins that are encoded by genes present in the rickettsial genome in multiple copies [Andersson et al., 1998; McLeod et al., 2004; Renesto et al., 2005b]. The intracellular spreading mechanisms of SFG rickettsiae and TG rickettsiae are different. SFG rickettsiae induce actin polymerization and move within host cells, which allows them to invade the neighboring cells without cell damaging the initially infected cells [Heinzen et al., 1993; Jeng et al., 2004; Gouin et al., 2004]. In contrast, TG rickettsiae are not motile within the cells and can only infect adjacent cells when the bacterial load increases (5-8 times greater than that observed for SFG) and induces host cell lysis [Hackstadt, 1996]. Interestingly, the intracellular motility of Rickettsia species is not associated with virulence, unlike Shigella flexneri [Heindl et al., 2010] and Listeria monocytogenes [Vazquez-Boland et al., 2001]. Avirulent rickettsiae (Rickettsia montana and avirulent strains of $R$. rickettsii) also 


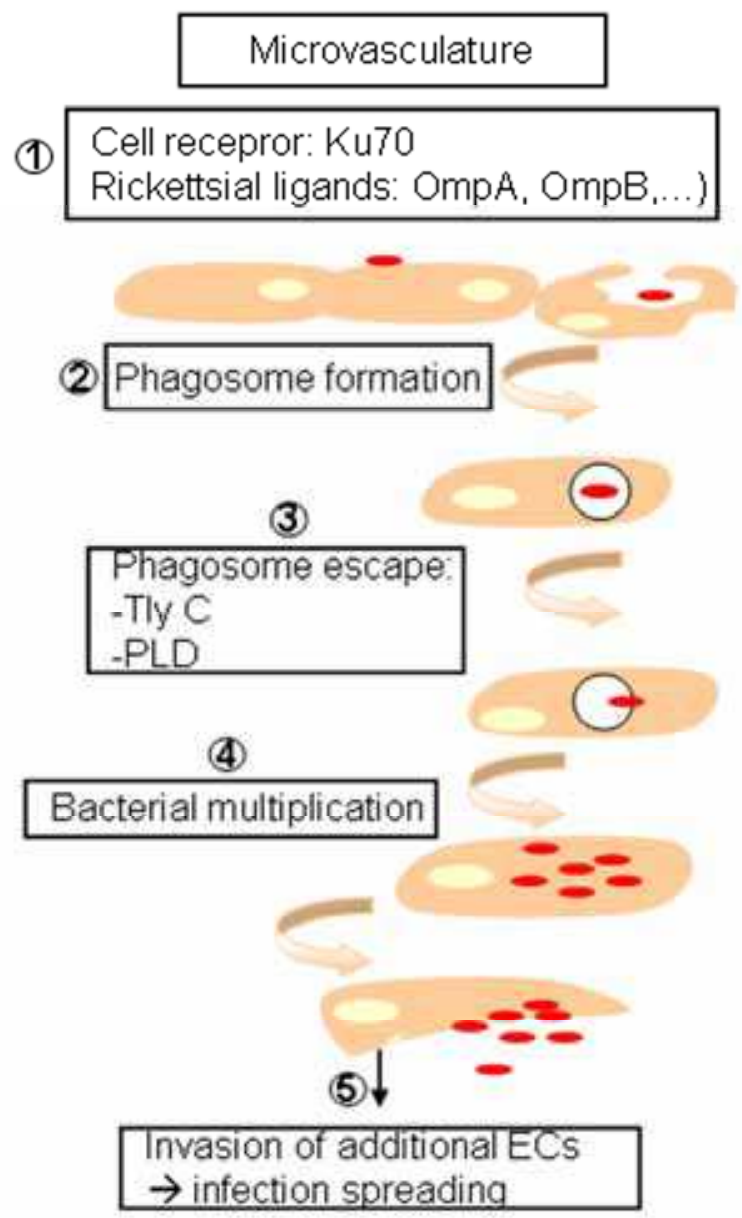

Fig. 3. Hypothetical Rickettsia-endothelial cell interactions After attachment to the endothelial cell receptors Ku70 using adhesins proteins (1), rickettsiae are ingested (2) but rapidly escape from phagosomes using PLD and Tly C proteins (3) and replicate in the cytoplasm (4). SFG rickettsiae spread directly to neighbouring cells via actin polymerization without cell damages. TG rickettsiae are released in the extracellular space after damages of infected cells; they infect adjacent cells leading to infection widespread.

induce actin tails [Heinzen et al., 1993], which indicates that other factors mediate rickettsial virulence. Previous studies have suggested that actin polymerization is dependent upon expression of the Rick A protein, although additional data suggest that Rick A is not the sole protein involved in rickettsial motility. For example, $R$. typhi induces the formation of short actin tails even in the absence of Rick A [Heinzen et al., 1993]. In addition, Rickettsia raoultii, which belongs to the SFG, expresses Rick A but is unable to mobilize actin [Balraj et al., 2008]. The Sca 2 (surface cell antigen 2) protein may also be involved in the actin-based motility of $R$. rickettsii [Kleba et al., 2010]; however, Rickettsia peacockii, which is a member of the SFG that does not exhibit actin-based motility, expresses an apparently intact Sca 2 
ortholog and does not express Rick A [Simser et al., 2005]. Thus, the data indicate that the actin-based motility of rickettsiae is a complex process that involves the Rick A and Sca 2 proteins, as well as other unidentified proteins. A large fraction of the rickettsial genome encodes proteins with unknown functions, and no known homologs of these proteins exist in the current databases.
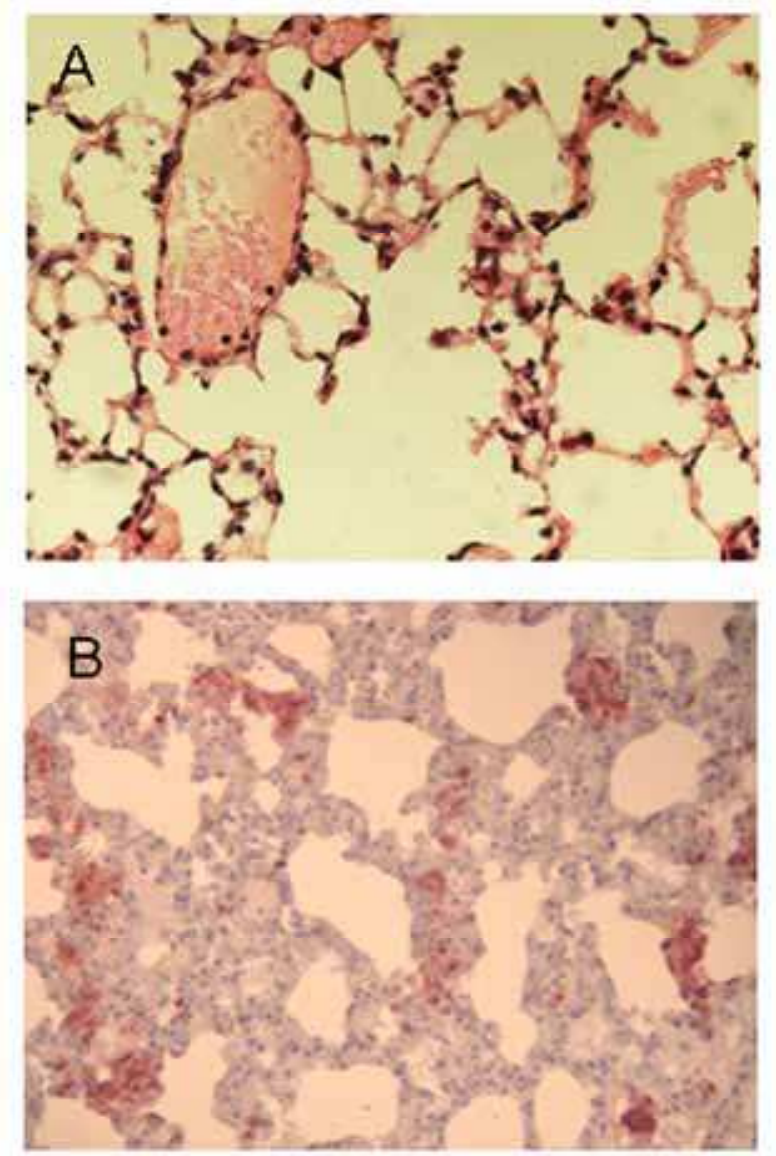

Fig. 4. Lung lesions induced by $R$. prowazekii Mice are infected with $R$. prowazekii for 7 days. Sections $(5 \mu \mathrm{m})$ of paraffin-embedded lungs are stained with hematoxylin-eosin to assess the presence of lesions. They are also incubated with rabbit anti- $R$. prowazekii polyclonal antibodies, and bacteria are revealed using biotin-conjugated antibodies and peroxidaselabeled streptavidin. A. Edema in the airways. B. massive $R$. prowazekii infection (red brown staining) is shown in the inflammatory infiltrates. A, B: original magnifications, X 250.

\section{Endothelium and pathophysiology of rickettsioses}

As endothelial infection progresses endothelial dysfunction progressively increases, which results in the associated disease symptoms. Endothelial cell dysfunction in vital organs such 
as the lungs and brain may cause the high morbidity and the mortality associated with rickettsioses. Microscopic endothelial injury includes increased vascular permeability; infiltration of plasma fluid, plasma proteins and mononuclear cells into the surrounding tissues; the formation of hemorrhagic foci (figure 2B); edema (figure 4A); and inflammatory lesions (figure 4B).

Several mechanisms may explain the increased permeability of blood vessels during rickettsial infections. During the early stages of infection, the endothelial cells demonstrate increased permeability, although they do not die. Rickettsiae binding to the endothelial cells may stimulate signal transduction pathways in the endothelial cells, which results in remodeling of the actin cytoskeleton and changes in the junction proteins. The cellular junctions maintain the vascular integrity and mediate anchorage to the actin microfilaments through the vascular endothelial cadherin and catenin proteins [Dejana et al., 1999; Bazzoni and Dejana E., 2004]. A previous study has shown that within 24 hours after $R$. rickettsii infection the vascular permeability is increased, and the $\beta$ and p120 catenin proteins dissociate from the inter-endothelial cellular junctions [Woods and Olano J. P., 2008].

One parameter to measure endothelial damage is to quantify the number of circulating endothelial cells [Brevetti et al., 2008]. A previous study has shown that the number of circulating endothelial cells increases in individuals infected with rickettsiae because the infected endothelial cells detach [George et al., 1993]. Endothelial cell detachment is not observed at the beginning of the disease because at this stage rickettsiae, as other strictly intracellular organisms, are within the cells and do not induce host cell death. One major strategy employed by rickettsiae to survive and replicate within their host cells is to inhibit endothelial cell apoptosis via NF-kB activation [Sahni et al., 1998; Joshi et al., 2003; Sporn et al., 1997]. NF- $\mathrm{kB}$ is a transcription factor that triggers an inflammatory response during rickettsial infection of the endothelial cells. Interestingly, in an in vitro system where endothelial cells were infected with a virulent $R$. prowazekii strain, the expression of proapoptotic genes, such as $B c l$ 2, caspase 8 and Naip was decreased; moreover, expression of the interferon type I (IFN-I)-inducible genes was inhibited [Bechah et al., 2010]. This response suggests that the survival of rickettsiae within their host cells depends on a combination of several mechanisms. The death and the subsequent detachment of infected endothelial cells in the later stages of infection may be caused by a marked increased in the bacterial load, especially with the TG rickettsiae; previous studies have also shown that apoptotic/necrotic cell death may be mediated by $\mathrm{CD}^{+}$cytotoxic $\mathrm{T}$ lymphocytes [Feng et al., 1997; Walker et al., 1994].

The increased vascular permeability during rickettsial infection may also be mediated by the production of cytokines and chemokines. In vivo and in vitro studies have shown that rickettsial infection of endothelial cells stimulates the release of proinflammatory cytokines, such as IL-1a, IL-6 and IL-8 [Sporn and Marder V. J., 1996; Oristrell et al., 2004; Damas et al., 2009], as well as the secretion of chemokines, such as CCL-2, CCL-5, CXCL-9, CXCL-10 and CX3CL-1 [Bechah et al., 2008; Bechah et al., 2007; Valbuena et al., 2003; Valbuena and Walker D. H., 2005]. Additional in vitro and in vivo studies have also shown that infection increases the expression of adhesive molecules, such as E-selectin, intercellular adhesion molecule-1 (ICAM-1) and vascular cell adhesion molecule-1 (VCAM-1) [Dignat-George et al., 1997; Damas et al., 2009]; these adhesive molecules regulate leukocyte movement between the circulation and the surrounding tissues. 


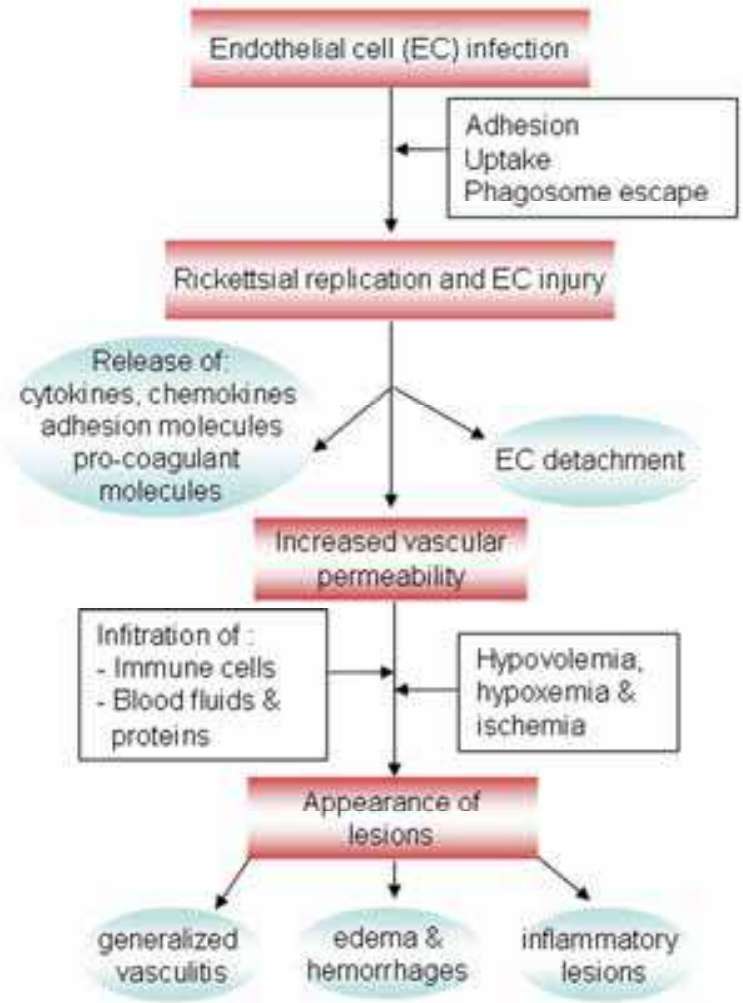

Fig. 5. Schematic representation of the natural history of rickettsial infections This representation of rickettsial infections is based on both in vitro and in vivo data. Infection of endothelial cells is followed by endothelial dysfunction. Several phenotypic and physiological disorders occur: expression and release of adhesion molecules, cytokines, chemokines as well as procoagulant molecules. These disorders lead to increased vascular permeability and the passage of blood molecules and inflammatory cells from vessels to interstitial space. They also lead to the alteration of coagulation pathway. Consequently, edema, microhemorrhages and inflammatory lesions appear as well as hypovolemia, shock with multiple organ dysfunctions as major manifestations.

In addition, rickettsial infection of the endothelial cells induces the secretion of prostaglandins, leukotrienes and nitric oxide (NO) [Walker et al., 1990; Rydkina et al., 2006; Woods et al., 2005], which are vasoactive mediators that increase vascular permeability. Prostaglandins and leukotrienes are generated from arachidonic acid by the cyclooxygenase (COX) enzymes, which are controlled by heme oxygenase (HO-1) [Haider et al., 2002; Rydkina et al., 2002]. In vitro and in vivo studies of rickettsial infection have shown that increased COX-2 expression in endothelial cells is related to increased prostaglandin secretion, which may explain some of the clinical manifestations of rickettsioses, such as pain, fever and inflammation. $\mathrm{NO}$ is synthesized from L-arginine by endothelial NO synthase (eNOS), and the expression level of eNOS rapidly increases after rickettsial infection [Walker et al., 1997]. NO increases the vascular permeability of endothelial cells 
[Woods et al., 2005] and plays a role in inducing rickettsial death [Feng and Walker D. H., 2000; Walker et al., 1997]. Correspondingly, the inhibition of NO generation increases the rickettsial burden in infected endothelial cells [Walker et al., 1997].

In addition to stimulating the release of cytokines/chemokines and vasoactive mediators, rickettsial endothelial cell infection also induces the release of pro-coagulant proteins, such as thrombomodulin, tissue factor, plasminogen activator inhibitor, platelet activating factor and von Willebrand factor both in vitro and in vivo [Elghetany and Walker D. H., 1999; Schmaier et al., 2001; Teysseire et al., 1992; Shi et al., 1996; Bechah et al., 2008; Lorant et al., 1995; Schmaier et al., 2001]. The release of pro-coagulant proteins may explain why thrombosis is associated with severe forms of rickettsioses.

Collectively, these changes to be in the endothelium during infection induce massive transmigration and infiltration of blood components and immune cells into the interstitial space. The subsequent hypovolemia contributes to shock and decreases the supply of nutrients and oxygen (perfusion) to various organs; as a consequence, multiple organ dysfunction, such as renal and cardiac failure, may be observed. The infiltration of blood components and inflammatory cells into the interstitial space leads to edema, microhemorrhages and inflammatory lesions that are mainly composed of infiltrating mononuclear cells; all of these symptoms are characteristic for rickettsial infection (figure 5). The increased transmigration of leukocytes may further increase tissue damage because these cells release proteases and oxygen radicals. We have recently shown that leukocytes that migrate throughout $R$. prowazekii-infected endothelial cells secrete increased levels of inflammatory and procoagulant mediators and may subsequently recruit additional immune cells [Bechah et al., 2008].

\section{Conclusions}

Rickettsioses are infectious diseases that target endothelial cells and cause endothelial dysfunction. The hallmark of rickettsial infections is widespread vascular injury that results in increased permeability of the endothelium and the escape of fluids and cells from the blood vessels into the interstitial space. This leakage ultimately results in edema, microhemorrhages, rashes and mononuclear cell infiltration around vessels and into surrounding tissues that form the characteristic lesions of rickettsioses (vasculitis). Changes in vital organs, such as the brain and lungs, induce hypoxemia, compression and increase oxidative stress, which result in a high morbidity and mortality. The leakage of blood fluids induces hypovolemia and ischemia in the affected organs, whereas other organs may be affected as a result of poor blood perfusion. Finally, cell death and an exaggerated host response with pro-coagulant activity in small vessels may lead to the development of occlusive thrombosis. We believe that understanding the endothelial cell dysfunction caused by rickettsioses may provide new insights to prevent the severity and the progression of rickettsial diseases. Finally, the treatment of vasculitis induced by rickettsiae depends on the bacterial control by antibiotics. However, as vasculitis may also be exacerbated in patients through excessive host response, the understanding of the mechanisms governing inflammatory responses could improve patient follow-up and avoid any squeals.

\section{References}

Ait-Oufella H, Maury E, Lehoux S, Guidet B, Offenstadt G. (2010). The endothelium: physiological functions and role in microcirculatory failure during severe sepsis. Intensive Care Med. 36 1286-1298. 
Ait-Oufella H, Salomon B L, Potteaux S, Robertson A K, Gourdy P, Zoll J, Merval R, Esposito B, Cohen J L, Fisson S, Flavell R A, Hansson G K, Klatzmann D, Tedgui A, Mallat Z. (2006). Natural regulatory $T$ cells control the development of atherosclerosis in mice. Nat. Med. 12 178-180.

Allaire E, Clowes A W. (1997). Endothelial cell injury in cardiovascular surgery: the intimal hyperplastic response. Ann. Thorac. Surg. 63 582-591.

Andersson JO, Andersson S G E. (1999). Genome degradation is an ongoing process in Rickettsia. Mol. Biol. Evol. 16 1178-1191.

Andersson SG, Zomorodipour A, Andersson J O, Sicheritz-Ponten T, Alsmark U C, Podowski R M, Naslund A K, Eriksson A S, Winkler H H, Kurland C G. (1998). The genome sequence of Rickettsia prowazekii and the origin of mitochondria. Nature 396 133-140.

Augustin HG, Kozian D H, Johnson R C. (1994). Differentiation of endothelial cells: analysis of the constitutive and activated endothelial cell phenotypes. Bioessays. 16 901-906.

Azad AF. (2007). Pathogenic rickettsiae as bioterrorism agents. Clin. Infect. Dis. 45 Suppl 1 S52-S55.

Balraj P, El K K, Vestris G, Espinosa L, Raoult D, Renesto P. (2008). RickA expression is not sufficient to promote actin-based motility of Rickettsia raoultii. PLoS. One 3 e2582.

Bazzoni G, Dejana E. (2004). Endothelial cell-to-cell junctions: molecular organization and role in vascular homeostasis. Physiol. Rev. 84 869-901.

Bechah Y, Capo C, Grau G E, Raoult D, Mege J L. (2007). A murine model of infection with Rickettsia prowazekii: implications for pathogenesis of epidemic typhus. Microbes. Infect. 9 898-906.

Bechah Y, Capo C, Raoult D, Mege J L. (2008). Infection of endothelial cells with virulent Rickettsia prowazekii increases the transmigration of leukocytes. II Infect. Dis. $197142-$ 147.

Bechah Y, El Karkouri K, Mediannikov O, Leroy Q, Pelletier N, Robert C, Medigue C, Mege J L, Raoult D. (2010). Genomic, proteomic, and transcriptomic analysis of virulent and avirulent Rickettsia prowazekii reveals its adaptive mutation capabilities. Genome Res. 20 655-663.

Bechah Y, Socolovschi C, Raoult D. (2011). Identification of rickettsial infections by using cutaneous swab specimens and PCR. Emerg. Infect. Dis. 17 83-86.

Blanc G, Ngwamidiba M, Ogata H, Fournier P E, Claverie J M, Raoult D. (2005). Molecular evolution of Rickettsia surface antigens: evidence of positive selection. Mol. Biol. Evol. 22 2073-2083.

Blanc G, Ogata H, Robert C, Audic S, Suhre K, Vestris G, Claverie J M, Raoult D. (2007). Reductive Genome Evolution from the Mother of Rickettsia. PLoS. Genet. 3 e14.

Brevetti G, Schiano V, Chiariello M. (2008). Endothelial dysfunction: a key to the pathophysiology and natural history of peripheral Atherosclerosis. 1971-11.

Damas JK, Davi G, Jensenius M, Santilli F, Otterdal K, Ueland T, Flo T H, Lien E, Espevik T, Froland S S, Vitale G, Raoult D, Aukrust P. (2009). Relative chemokine and adhesion molecule expression in Mediterranean spotted fever and African tick bite fever. I Infect. 58 68-75.

Davies PF. (1995). Flow-mediated endothelial mechanotransduction. Physiol. Rev. 75 519-560.

Dejana E, Bazzoni G, Lampugnani M G. (1999). Vascular endothelial (VE)-cadherin: only an intercellular glue? Exp. Cell Res. 252 13-19. 
Dignat-George F, Teysseire N, Mutin M, Bardin N, Lesaule G, Raoult D, Sampol J. (1997). Rickettsia conorii infection enhances vascular cell adhesion molecule-1- and intercellular adhesion molecule-1- dependent mononuclear cell adherence to endothelial cells. II Infect. Dis. 175 1142-1152.

Driskell LO, Yu X J, Zhang L, Liu Y, Popov V L, Walker D H, Tucker A M, Wood D O. (2009). Directed mutagenesis of the Rickettsia prowazekii pld gene encoding phospholipase D. Infect. Immun. 77 3244-3248.

Elghetany MT, Walker D H. (1999). Hemostatic changes in Rocky Mountain spotted fever and Mediterranean spotted fever. Am. d Clin. Pathol. 112 159-168.

Feng H, Popov V L, Yuoh G, Walker D H. (1997). Role of T lymphocyte subsets in immunity to spotted fever group Rickettsiae. I Immunol. 158 5314-5320.

Feng HM, Walker D H. (2000). Mechanisms of intracellular killing of Rickettsia conorii in infected human endothelial cells, hepatocytes, and macrophages. Infect. Immun. 68 6729-6736.

Feng HM, Whitworth T, Popov V, Walker D H. (2004). Effect of antibody on the rickettsiahost cell interaction. Infect. Immun. 72 3524-3530.

George F, Brouqui P, Boffa M C, Mutin M, Drancourt M, Brisson C, Raoult D, Sampol J. (1993). Demonstration of Rickettsia conorii-induced endothelial injury in vivo by measuring circulating endothelial cells, thrombomodulin and Von Willebrand factor in patients with mediterranean spotted fever. Blood. 82 2109-2116.

Gouin E, Egile C, Dehoux P, Villiers V, Adams J, Gertler F, Li R, Cossart P. (2004). The RickA protein of Rickettsia conorii activates the Arp2/3 complex. Nature. 427 457-461.

Hackstadt T. (1996). The biology of rickettsiae. Inf. Agents Dis. 5 127-143.

Haider A, Olszanecki R, Gryglewski R, Schwartzman M L, Lianos E, Kappas A, Nasjletti A, Abraham N G. (2002). Regulation of cyclooxygenase by the heme-heme oxygenase system in microvessel endothelial cells. el Pharmacol. Exp. Ther. 300 188-194.

Heindl JE, Saran I, Yi C R, Lesser C F, Goldberg M B. (2010). Requirement for formininduced actin polymerization during spread of Shigella flexneri. Infect. Immun. 78 193-203.

Heinzen RA, Hayes S F, Peacock M G, Hackstad T. (1993). Directional actin polymerization associated with spotted fever group rickettsia infection of Vero cells. Infect. Immun. 61 1926-1935.

Houhamdi L, Fournier P E, Fang R, Lepidi H, Raoult D. (2002). An experimental model of human body louse infection with Rickettsia prowazekii. J. Infect. Dis. 186 1639-1646.

Ishii H, Salem H H, Bell C E, Laposata E A, Majerus P W. (1986). Thrombomodulin, an endothelial anticoagulant protein, is absent from the human brain. Blood. 67 362365.

Jeng RL, Goley E D, D'Alessio J A, Chaga O Y, Svitkina T M, Borisy G G, Heinzen R A, Welch M D. (2004). A Rickettsia WASP-like protein activates the Arp2/3 complex and mediates actin-based motility. Cell. Microbiol. 6 761-769.

Joshi SG, Francis C W, Silverman D J, Sahni S K. (2003). Nuclear factor kappa B protects against host cell apoptosis during Rickettsia rickettsii infection by inhibiting activation of apical and effector caspases and maintaining mitochondrial integrity. Infect. Immun. 71 4127-4136. 
Kleba B, Clark T R, Lutter E I, Ellison D W, Hackstadt T. (2010). Disruption of the Rickettsia rickettsii Sca2 autotransporter inhibits actin-based motility. Infect. Immun. 78 22402247.

Li H, Walker D H. (1992). Characterization of rickettsial attachment to host cells by flow cytometry. Infect. Immun. 60 2030-2035.

Li H, Walker D H. (1998). RompA is a critical protein for the adhesion of Rickettsia rickettsii to host cells. Microbial. Pathogenesis. 24 289-298.

Lorant DE, Zimmerman G A, McIntyre T M, Prescott S M. (1995). Platelet-activating factor mediates procoagulant activity on the surface of endothelial cells by promoting leukocyte adhesion. Semin. Cell Biol. 6 295-303.

Marelli-Berg FM, Hargreaves R E, Carmichael P, Dorling A, Lombardi G, Lechler R I. (1996). Major histocompatibility complex class II-expressing endothelial cells induce allospecific nonresponsiveness in naive T cells. el Exp. Med. 183 1603-1612.

McGettrick HM, Filer A, Rainger G E, Buckley C D, Nash G B. (2007). Modulation of endothelial responses by the stromal microenvironment: effects on leucocyte recruitment. Biochem. Soc. Trans. 35 1161-1162.

McLeod MP, Qin X, Karpathy S E, Gioia J, Highlander S K, Fox G E, McNeill T Z, Jiang H, Muzny D, Jacob L S, Hawes A C, Sodergren E, Gill R, Hume J, Morgan M, Fan G, Amin A G, Gibbs R A, Hong C, Yu X J, Walker D H, Weinstock G M. (2004). Complete genome sequence of Rickettsia typhi and comparison with sequences of other rickettsiae. cI Bacteriol. 186 5842-5855.

Merhej V, Royer-Carenzi M, Pontarotti P, Raoult D. (2009). Massive comparative genomic analysis reveals convergent evolution of specialized bacteria. Biol. Direct. 413.

Oristrell J, Sampere M, Amengual M J, Font B, Segura F. (2004). Plasma interleukin-6 levels in Mediterranean spotted fever. Eur. I Clin. Microbiol. Infect. Dis. 23 417-418.

Oster CN, Burke D S, Kenyon R H, Ascher M S, Harber P, Pedersen C E, Jr. (1977). Laboratory-acquired Rocky Mountain spotted fever. The hazard of aerosol transmission. N. Engl. el Med. 297 859-863.

Pober JS, Orosz C G, Rose M L, Savage C O. (1996). Can graft endothelial cells initiate a host anti-graft immune response? Transplantation. 61 343-349.

Renesto P, Azza S, Dolla A, Fourquet P, Vestris G, Gorvel J P, Raoult D. (2005a). Rickettsia conorii and $R$. prowazekii proteome analysis by 2DE-MS: a step toward functional analysis of Rickettsial genomes. Ann. NY Acad. Sci. 1063 90-93.

Renesto P, Dehoux P, Gouin E, Touqui L, Cossart P, Raoult D. (2003). Identification and characterization of a phospholipase D-superfamily gene in rickettsiae. I Infect. Dis. 188 1276-1283.

Renesto P, Ogata H, Audic S, Claverie J M, Raoult D. (2005b). Some lessons from Rickettsia genomics. FEMS. Microbiol. Rev. 29 99-117.

Renesto P, Samson L, Ogata H, Azza S, Fourquet P, Gorvel J P, Heinzen R A, Raoult D. (2006). Identification of two putative rickettsial adhesins by proteomic analysis. Res. Microbiol. 157 605-612.

Rydkina E, Sahni A, Baggs R B, Silverman D J, Sahni S K. (2006). Infection of human endothelial cells with spotted Fever group rickettsiae stimulates cyclooxygenase 2 expression and release of vasoactive prostaglandins. Infect. Immun. 74 5067-5074. 
Rydkina E, Sahni A, Silverman D J, Sahni S K. (2002). Rickettsia rickettsii infection of cultured human endothelial cells induces heme oxygenase 1 expression. Infect. Immun. 70 4045-4052.

Saah AJ. (2000). Rickettsia prowazekii (Epidemic or louse-borne typhus). In: Principles and Practice of Infectious Diseases. Mandell GL, Bennett JE, Dolin R, eds. Philadelphia, PA: Churchill Livingstone; pp 2050-2053.

Sahni SK, Vanantwerp D J, Eremeeva M E, Silverman D J, Marder V J, Sporn L A. (1998). Proteasome-independent activation of nuclear factor kappa-B in cytoplasmic extracts from human endothelial cells by Rickettsia rickettsii. Infect. Immun. 66 18271833.

Schmaier AH, Srikanth S, Elghetany M T, Normolle D, Gokhale S, Feng H M, Walker D H. (2001). Hemostatic/fibrinolytic protein changes in $\mathrm{C} 3 \mathrm{H} / \mathrm{HeN}$ mice infected with Rickettsia conorii--a model for Rocky Mountain spotted fever. Thromb. Haemost. 86 871-879.

Shi RJ, Simpsonhaidaris P J, Marder V J, Silverman D J, Sporn L A. (1996). Increased expression of plasminogen activator inhibitor-1 in $R$ - rickettsii-infected endothelial cells. Thromb. Haemost. 75 600-606.

Simser JA, Rahman M S, Dreher-Lesnick S M, Azad A F. (2005). A novel and naturally occurring transposon, ISRpe1 in the Rickettsia peacockii genome disrupting the rickA gene involved in actin-based motility. Mol. Microbiol. 58 71-79.

Sporn LA, Marder V J. (1996). Interleukin-1 alpha production during Rickettsia rickettsii infection of cultured endothelial cells: Potential role in autocrine cell stimulation. Infect. Immun. 64 1609-1613.

Sporn LA, Sahni S K, Lerner N B, Marder V J, Silverman D J, Turpin L C, Schwab A L. (1997). Rickettsia rickettsii infection of cultured human endothelial cells induces NF$\mathrm{\kappa B}$ activation. Infect. Immun. 65 2786-2791.

Steinsiepe KF, Weibel E R. (1970). [Electron microscopic studies on specific organelles of endothelial cells in the frog (Rana temporaria)]. Z. Zellforsch. Mikrosk. Anat. 108 105126.

Sumpio BE, Riley J T, Dardik A. (2002). Cells in focus: endothelial cell. Int. I Biochem. Cell Biol. 34 1508-1512.

Teysseire N, Arnoux D, George F, Sampol J, Raoult D. (1992). Von Willebrand factor release, thrombomodulin and tissue factor expression in Rickettsia conorii infected endothelial cells. Infect. Immun. 60 4388-4393.

Teysseire N, Boudier J A, Raoult D. (1995). Rickettsia conorii entry into vero cells. Infect. Immun. 63 366-374.

Tse D, Stan R V. (2010). Morphological heterogeneity of endothelium. Semin. Thromb. Hemost. 36 236-245.

Uchiyama T. (2003). Adherence to and invasion of Vero cells by recombinant Escherichia coli expressing the outer membrane protein rOmpB of Rickettsia japonica. Ann. N. Y. Acad. Sci. 990 585-590.

Valbuena G, Bradford W, Walker D H. (2003). Expression analysis of the T-cell-targeting chemokines CXCL-9 and CXCL-10 in mice and humans with endothelial infections caused by rickettsiae of the spotted fever group. Am. JPathol. 163 1357-1369. 
Valbuena G, Walker D H. (2005). Expression of CX3CL1 (fractalkine) in mice with endothelial-target rickettsial infection of the spotted-fever group. Virchows Arch. 446 21-27.

Vazquez-Boland JA, Kuhn M, Berche P, Chakraborty T, Dominguez-Bernal G, Goebel W, Gonzalez-Zorn B, Wehland J, Kreft J. (2001). Listeria pathogenesis and molecular virulence determinants. Clin. Microbiol. Rev. 14 584-640.

Walker DH, Popov V L, Crocquet-Valdes P A, Welsh C J, Feng H M. (1997). Cytokineinduced, nitric oxide-dependent, intracellular antirickettsial activity of mouse endothelial cells. Lab. Invest. 76 129-138.

Walker DH, Popov V L, Wen J, Feng H M. (1994). Rickettsia conorii infection of C3H/HeN mice. Lab. Invest. 70 358-368.

Walker TS. (1984). Rickettsial interactions with human endothelial cells in vitro: adherence and entry. Infect. Immun. 44 205-210.

Walker TS, Brown J S, Hoover C S, Morgan D A. (1990). Endothelial prostaglandin secretion: effects of typhus rickettsiae. I Infect. Dis. 162 1136-1144.

Wells GM, Woodward T E, Fiset P, Hornick R B. (1978). Rocky mountain spotted fever caused by blood transfusion. el Amer. Med. Assoc. 239 2763-2765.

Whitworth T, Popov V L, Yu X J, Walker D H, Bouyer D H. (2005). Expression of the Rickettsia prowazekii pld or tlyC gene in Salmonella enterica serovar Typhimurium mediates phagosomal escape. Infect. Immun. 73 6668-6673.

Woods ME, Olano J P. (2008). Host defenses to Rickettsia rickettsii infection contribute to increased microvascular permeability in human cerebral endothelial cells. J Clin. Immunol. 28 174-185.

Woods ME, Wen G, Olano J P. (2005). Nitric oxide as a mediator of increased microvascular permeability during acute rickettsioses. Ann. N. Y. Acad. Sci. 1063 239-245. 


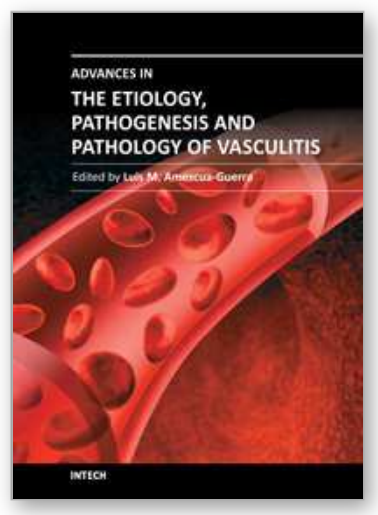

\author{
Advances in the Etiology, Pathogenesis and Pathology of \\ Vasculitis \\ Edited by Dr. Luis M Amezcua-Guerra
}

ISBN 978-953-307-651-5

Hard cover, 438 pages

Publisher InTech

Published online 17, October, 2011

Published in print edition October, 2011

This book represents the culmination of the efforts of a group of outstanding experts in vasculitis from all over the world, who have endeavored to devote their work to this book by keeping both the text and the accompanying figures and tables lucid and memorable. Here, you will find an amalgam between evidencebased medicine to one based on eminence, through an exciting combination of original contributions, structured reviews, overviews, state-of the-art articles, and even the proposal of novel pathogenetic models of disease. The book contains contributions on the etiology and pathology of vasculitis, the potential role of endothelial cells and cytokines in vascular damage and repair as well as summaries of the latest information on several primary and secondary vasculitis syndromes. It also covers selected topics such as organ-specific vasculitic involvement and quality of life issues in vasculitis. The editor and each of the authors invite you to share this journey through one of the most exciting fields of the medicine, the world of Vasculitis.

\title{
How to reference
}

In order to correctly reference this scholarly work, feel free to copy and paste the following:

Yassina Bechah, Christian Capo and Jean-Louis Mege (2011). Vasculitis: Endothelial Dysfunction During Rickettsial Infection, Advances in the Etiology, Pathogenesis and Pathology of Vasculitis, Dr. Luis M AmezcuaGuerra (Ed.), ISBN: 978-953-307-651-5, InTech, Available from: http://www.intechopen.com/books/advancesin-the-etiology-pathogenesis-and-pathology-of-vasculitis/vasculitis-endothelial-dysfunction-during-rickettsialinfection

\section{INTECH}

open science | open minds

\section{InTech Europe}

University Campus STeP Ri

Slavka Krautzeka 83/A

51000 Rijeka, Croatia

Phone: +385 (51) 770447

Fax: +385 (51) 686166

www.intechopen.com

\section{InTech China}

Unit 405, Office Block, Hotel Equatorial Shanghai

No.65, Yan An Road (West), Shanghai, 200040, China

中国上海市延安西路65号上海国际贵都大饭店办公楼405单元

Phone: +86-21-62489820

Fax: $+86-21-62489821$ 
(C) 2011 The Author(s). Licensee IntechOpen. This is an open access article distributed under the terms of the Creative Commons Attribution 3.0 License, which permits unrestricted use, distribution, and reproduction in any medium, provided the original work is properly cited. 